\title{
CYP3A4 Inhibitors Isolated from Licorice
}

\author{
Sachiko Tsukamoto, Maki Aburatani, Tomohiro Yoshida, Yuko Yamashita, \\ Ahmed Atef El-BeIH, and Tomihisa OHTA* \\ Graduate School of Natural Science and Technology, Kanazawa University; Kakuma-machi, Kanazawa 920-1192, Japan. \\ Received April 28, 2005; accepted June 25, 2005; published online July 1, 2005
}

\begin{abstract}
The extract of licorice (Glycyrrhiza uralensis FISHER, Leguminosae) showed CYP3A4 inhibitory activity with the $\mathrm{IC}_{50}$ value of $0.022 \mathrm{mg} / \mathrm{ml}$. Bioassay-guided purification afforded nine compounds, 3-( $p$-hydroxyphenyl)propionic acid (1), isoliquiritigenin (2), (3R)-vestitol (3), licopyranocoumarin (4), 4-hydroxyguaiacol apioglucoside (5), liquiritin (6), liquiritigenin 7,4'-diglucoside (7), liquiritin apioside (8), and glucoliquiritin apioside (9). Among these compounds, 3, 7, and 5 showed potent CYP3A4 inhibitory activities with $\mathrm{IC}_{50}$ values of 3.6, 17, and $20 \mu_{\mathrm{M}}$, respectively. Glycyrrhizin (10), a main constituent of licorice, however, was inactive for CYP3A4 inhibition.
\end{abstract}

Key words Glycyrrhiza uralensis; licorice; CYP3A4 inhibitory activity

Cytochrome P450 (CYP) enzymes are responsible for metabolism of a wide range of endogeneous compounds and xenobiotics, e.g. drug molecules, pollutants, and environmental compounds. Among members of the CYP enzyme family, CYP3A4 is the most abundant enzyme in human liver microsomes and intestinal epithelium; approximately $30 \%$ of the total CYP was suggested to be CYP3A4, ${ }^{1)}$ and more than $50 \%$ of clinically used drugs are oxidized by CYP $3 \mathrm{~A} 4 .^{2,3)} \mathrm{It}$ is well known that concomitant oral administration of several foods and herbs affects drug metabolism in humans by inhibiting CYP3A4 activity. In the course of our study on CYP inhibitors from foods, we have reported the isolation and structure elucidation of CYP inhibitors from grapefruit (Citrus paradisii) juice, ${ }^{4-6)}$ white pepper, Piper nigrum, ${ }^{7,8)}$ strawberry fruit, Fragaria ananassa, ${ }^{9)}$ and the commercially available black cohosh, Cimicifuga racemosa ${ }^{10)}$ Licorice is prescribed in many Chinese traditional medicines and has been reported to contain flavonoids and triterpenoids. ${ }^{11-19)}$ Recently, we found that the extract of licorice (Glycyrrhiza uralensis FISHER, Leguminosae) showed potent CYP3A4 inhibitory activity with the $\mathrm{IC}_{50}$ value of $0.022 \mathrm{mg} / \mathrm{ml}$. This paper reports the isolation, structure identification, and CYP inhibitory activity of the constituents of licorice.

\section{MATERIALS AND METHODS}

General Procedures Optical rotations were determined with a Horiba SEPA-300 high sensitive polarimeter. NMR spectra were recorded on a JEOL GSX500 NMR spectrometer. Mass spectra were measured on a JEOL SX-102 mass spectrometer.

Plant Materials The rhizomes of G. uralensis were purchased from Tochimoto Co., Ltd. (Osaka, Japan). A voucher specimen is deposited in the Laboratory of Pharmacognosy and Chemistry of Natural Products, Graduate School of Natural Science and Technology, Kanazawa University, Japan.

Isolation of Compounds 1-9 The rhizomes $(0.5 \mathrm{~kg})$ of G. uralensis were extracted with methanol $(\mathrm{MeOH})(31 \times 3)$ at room temperature. The extract was evaporated in vacuo, and the residue was partitioned between ethyl acetate (EtOAc) and water $\left(\mathrm{H}_{2} \mathrm{O}\right)$. The aqueous fraction was then partitioned between butanol $(\mathrm{BuOH})$ and water. The EtOAc soluble fraction $(34.7 \mathrm{~g})$ was subjected to column chromatography on silica gel with hexane/EtOAc followed by ODS col- umn chromatography with $\mathrm{MeOH} / \mathrm{H}_{2} \mathrm{O}$ to afford $\mathbf{1}-\mathbf{4}$ (Fig. 1). The $\mathrm{BuOH}$ soluble fraction $(34.9 \mathrm{~g}$ ) was subjected to column chromatography on ODS with $\mathrm{MeOH} / \mathrm{H}_{2} \mathrm{O}$ followed by ODS HPLC with $\mathrm{MeOH} / \mathrm{H}_{2} \mathrm{O}$ to afford $\mathbf{6}$ and $\mathbf{8}$. The aqueous fraction $(31.3 \mathrm{~g})$ was subjected to column chromatography on ODS with $\mathrm{MeOH} / \mathrm{H}_{2} \mathrm{O}$ followed by ODS HPLC with $\mathrm{MeOH} / \mathrm{H}_{2} \mathrm{O}$ to afford 5, 7, and 9 .

Assay of CYP3A4 Inhibition CYP3A4 activity was measured based on nifedipine oxidation. Various amounts $(0-10 \mu \mathrm{M}$, final concentration) of samples in $1 \mu \mathrm{l}$ of dimethylsulfoxide (DMSO) were added to $192 \mu \mathrm{l}$ of $100 \mathrm{~mm}$ phosphate buffer ( $\mathrm{pH}$ 7.4) containing $50 \mu \mathrm{M}$ nifedipine (Wako Pure Chemical Industries, Ltd., Osaka, Japan), $5 \mathrm{~mm}$ glucose-6-phosphate (Oriental Yeast Co., Ltd., Tokyo, Japan), $0.5 \mathrm{~mm} \beta$-NADP ${ }^{+}$(Oriental Yeast Co., Ltd.), $0.5 \mathrm{~mm}$ $\mathrm{MgCl}_{2}$, and $4.3 \mu \mathrm{g} / \mathrm{ml}$ glucose-6-phosphate dehydrogenase (Oriental Yeast Co., Ltd.), and the mixture was incubated at $37^{\circ} \mathrm{C}$ for $5 \mathrm{~min}$. Human CYP3A4 (Gentest Co., Woburn, MA, U.S.A.) was also preincubated in $7 \mu \mathrm{l}$ of the buffer at $37^{\circ} \mathrm{C}$ for $5 \mathrm{~min}$ and added to the above sample mixture. After incubation at $37^{\circ} \mathrm{C}$ for $1 \mathrm{~h}$, the reaction was quenched by the addition of $100 \mu \mathrm{l}$ of $\mathrm{MeOH}$. After adding $3.7 \mu \mathrm{g}$ of 6methoxycarbonyl-5-methyl-7-(2-nitrophenyl)-4,7-dihydrofuro[3,4-b]pyridin-1-(3H)-one in $1 \mu 1$ of DMSO as an internal standard, the reaction mixture was extracted with $1 \mathrm{ml}$ of ether, and the ether layer was evaporated. The residue was dissolved in $100 \mu \mathrm{l}$ of $\mathrm{MeOH}$, and an aliquot $(20 \mu \mathrm{l})$ was analyzed by reverse-phase HPLC (column, TSK-gel ODS-120T, $4.6 \mathrm{~mm}$ i.d. $\times 150 \mathrm{~mm}$; mobile phase, $64 \%$ $\mathrm{MeOH}-\mathrm{H}_{2} \mathrm{O}$; flow rate, $1.0 \mathrm{ml} / \mathrm{min}$; detection, UV $254 \mathrm{~nm}$ ); retention times: $2.9 \mathrm{~min}$ for the internal standard, $4.0 \mathrm{~min}$ for the nifedipine metabolite (nifedipine pyridine), and $5.5 \mathrm{~min}$ for nifedipine. The value of $\mathrm{IC}_{50}$, the concentration required for $50 \%$ inhibition of CYP3A4 activity, was calculated from the data of duplicate measurements.

\section{RESULTS AND DISCUSSION}

The rhizomes of $G$. uralensis were extracted with $\mathrm{MeOH}$. The extract showed CYP3A4 inhibitory activity with the $\mathrm{IC}_{50}$ value of $0.022 \mathrm{mg} / \mathrm{ml}$. The extract was then separated into EtOAc, $\mathrm{BuOH}$, and $\mathrm{H}_{2} \mathrm{O}$ soluble fractions. The three fractions were tested for CYP inhibitory activity and showed 97, 98 , and $61 \%$ inhibition, respectively, at the concentration of 

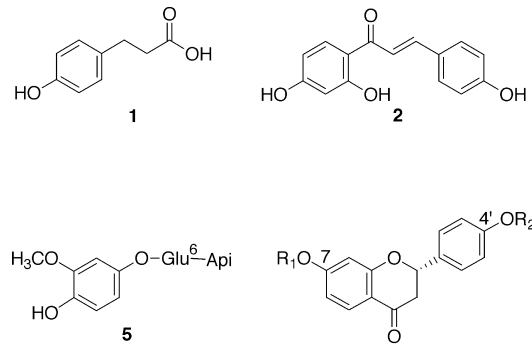

Fig. 1. Compounds Isolated from Glycyrrhiza uralensis

$0.25 \mathrm{mg} / \mathrm{ml}$. The EtOAc soluble fraction of the extract was subjected to column chromatography on silica gel followed by ODS column chromatography to afford 1 (55.2 $\mathrm{mg}$, $\left.1.1 \times 10^{-2} \%\right), 2\left(13.4 \mathrm{mg}, 2.7 \times 10^{-3} \%\right){ }^{17)} \mathbf{3}(4.7 \mathrm{mg}, 9.4 \times$ $\left.10^{-4} \%\right),{ }^{20)}$ and $4\left(238.0 \mathrm{mg}, 4.8 \times 10^{-2} \%\right) .^{12,15)}$ The $\mathrm{BuOH}$ soluble fraction of the extract was subjected to ODS column chromatography followed by ODS HPLC to afford $6(5.2 \mathrm{mg}$, $\left.1.0 \times 10^{-3} \%\right)^{14)}$ and $8\left(22.9 \mathrm{mg}, 4.6 \times 10^{-3} \%\right) .^{14,18)}$ The aqueous fraction of the extract was subjected to ODS column chromatography followed by ODS HPLC to afford 5 (2.0 $\left.\mathrm{mg}, 4.0 \times 10^{-4 \%}\right),{ }^{21,22)} 7\left(45.2 \mathrm{mg}, 9.0 \times 10^{-3} \%\right),{ }^{13)}$ and 9 $\left(10.9 \mathrm{mg}, 2.2 \times 10^{-3} \%\right)^{18)}$ (Fig. 1). The structures were identified by comparison of their ${ }^{1} \mathrm{H}-$ and ${ }^{13} \mathrm{C}-\mathrm{NMR}$, MS, and $[\alpha]_{\mathrm{D}}$ data with the reported values. CYP3A4 inhibitory activities of compounds isolated from G. uralensis were measured using human CYP3A4 (Table 1). Among nine compounds isolated, $\mathbf{3}, \mathbf{7}$, and $\mathbf{5}$ showed potent CYP3A4 inhibitory activities with $\mathrm{IC}_{50}$ values of $3.6,17$, and $20 \mu \mathrm{M}$, respectively. Glycyrrhizin (10) (Wako Pure Chemical Industries, Ltd., Osaka, Japan), a main constituent of licorice, however, was a poor CYP3A4 inhibitor. Flavone glycosides containing sugar moieties at both C-7 and C-4' positions, 7 and 9, showed more potent CYP3A4 inhibitory activities with $\mathrm{IC}_{50}$ values of 17 and $87 \mu \mathrm{M}$, respectively, than the corresponding C-7 deglucosyl derivatives, 6 and $\mathbf{8}\left(\mathrm{IC}_{50}, 57\right.$ and $655 \mu \mathrm{M}$, respectively). Compounds 8 and 9 correspond to apiosides of $\mathbf{6}$ and $\mathbf{7}$ at the $\mathrm{C}-2$ position of the $4^{\prime}$ - $O$-glucosyl moieties, respectively, and less hydrophilic glucosides $\mathbf{6}$ and $\mathbf{7}$ showed more potent CYP inhibitory activities than $\mathbf{8}$ and $\mathbf{9}$, respectively. These data suggest that the hydrophilicity and bulkiness of flavone glycosides play key roles in their exhibition of inhibitory activity against CYP3A4. Although the CYP inhibitory activity of the licorice extract and glabridin, an isoflavan derivative of licorice, were investigated so far, this is the first report of the bioassay-guided isolation of CYP3A4 inhibitors from licorice. ${ }^{23)}$ It is well known that CYP3A4 is involved in metabolism of a variety of endogeneous compounds and xenobiotics. Recently, three crystal structures of CYP3A4 that had been bound to the inhibitor metyrapone, bound to the substrate progesterone, and unliganded, were reported. ${ }^{24)}$ Contrary to the previous expectation, the active site of CYP3A4 was revealed to be small with little conformational change, although CYP3A4 is involved in the metabolism of a structurally wide range of compounds. The study of the structureactivity relationship of CYP3A4 inhibitors could be helpful to understand the interaction between CYP3A4 and ligands. The fact that the $\mathrm{IC}_{50}$ value of CYP3A4 inhibitory activity by the $\mathrm{MeOH}$ extract of licorice is $0.022 \mathrm{mg} / \mathrm{ml}$ implies that metabolism of nifedipin with a half-dose of one-day treatment is
Table 1. CYP3A4 Inhibitory Activity of Compounds Isolated from Licorice

\begin{tabular}{cccc}
\hline \hline Compd. & $\begin{array}{c}\mathrm{IC}_{50} \\
(\mu \mathrm{M})\end{array}$ & Compd. & $\begin{array}{c}\mathrm{IC}_{50} \\
(\mu \mathrm{M})\end{array}$ \\
\hline $\mathbf{1}$ & 48 & $\mathbf{6}$ & 57 \\
$\mathbf{2}$ & 29 & $\mathbf{7}$ & 17 \\
$\mathbf{3}$ & 3.6 & $\mathbf{8}$ & 655 \\
$\mathbf{4}$ & 32 & $\mathbf{9}$ & 87 \\
$\mathbf{5}$ & 20 & $\mathbf{1 0}$ & $b)$ \\
Ketoconazole $^{a)}$ & 0.11 & &
\end{tabular}

a) A typical CYP3A4 inhibitor. b) Compound $\mathbf{1 0}$ showed less than $50 \%$ inhibitory activity at the concentration of $1.2 \mathrm{~mm}$.

inhibited by one-twentyfifth amount of the licorice extract contained in the traditional Chinese prescription, Kakkon-to, for one-day treatment. Thus, it is important to evaluate the $\mathrm{IC}_{50}$ values of constituents in foods/herbs in order to avoid clinical risks due to interactions among orally administered drugs and concomitant foods/herbs.

\section{REFERENCES}

1) Shimada T., Yamazaki H., Mimura M., Inui Y., Guengerish F. P., J. Pharmacol. Exp. Ther, 270, $414-423$ (1994).

2) Guengerish F. P., Adv. Pharmacol., 43, 7 -35 (1997).

3) Rendic S., DiCarlo F. J., Drug Metab. Rev., 29, 413-580 (1997).

4) Ohta T., Nagahashi M., Hosoi S., Tsukamoto S., Bioorg. Med. Chem., 10, 969-973 (2002).

5) Ohta T., Maruyama T., Nagahashi K., Miyamoto Y., Hosoi S., Kiuchi F., Yamazoe Y., Tsukamoto S., Tetrahedron, 58, 6631-6635 (2002).

6) Ohta T., Miyamoto Y., Maruyama T., Kiuchi F., Tsukamoto S., Nat. Med., 56, 264-267 (2002).

7) Tsukamoto S., Cha B.-C., Ohta T., Tetrahedron, 58, 1667-1671 (2002).

8) Tsukamoto S., Tomise K., Miyakawa K., Cha B.-C., Abe T., Hamada Y., Hirota H., Ohta T., Bioorg. Med. Chem., 10, 2981-2985 (2002).

9) Tsukamoto S., Tomise K., Aburatani M., Onuki H., Hirota H., Ishiharajima E., Ohta T., J. Nat. Prod., 67, 1839-1841 (2004).

10) Tsukamoto S., Aburatani M., Ohta T., eCAM, 2, 223-226 (2005).

11) Nomura T., Fukai T., Fortschr. Chem. Org. Naturst., 73, 1-158 (1998).

12) Hatano T., Yasuhara T., Miyamoto K., Okuda T., Chem. Pharm. Bull., 36, 2286-2288 (1988).

13) Yahara S., Nishioka I., Phytochemistry, 23, 2108-2109 (1984).

14) Nakanishi T., Inada A., Kambayashi K., Yoneda K., Phytochemistry, 24, 339-341 (1985).

15) Hatano T., Yasuhara T., Fukuda T., Noro T., Okuda T., Chem. Pharm. Bull., 37, 3005-3009 (1989).

16) Kitagawa I., Hori K., Sakagami M., Hashiuchi F., Yoshikawa M., Ren J., Chem. Pharm. Bull., 41, 1350-1357 (1993).

17) Kitagawa I., Hori K., Uchida E., Chen W.-Z., Yoshikawa M., Ren J., Chem. Pharm. Bull., 41, 1567-1572 (1993).

18) Kitagawa I., Chen W.-Z., Hori K., Harada E., Yasuda N., Yoshikawa M., Ren J., Chem. Pharm. Bull., 42, 1056-1062 (1994).

19) Kitagawa I., Chen W.-Z., Hori K., Kobayashi M., Ren J., Chem. 
Pharm. Bull., 46, 1511-1517 (1998).

20) Yahara S., Ogata T., Saijo R., Konishi R., Yamahara J., Miyahara K., Nohara T., Chem. Pharm. Bull., 37, 979—987 (1989).

21) Sugiyama M., Kikuchi M., Phytochemistry, 30, 3147-3149 (1991).

22) Sibuya H., Takeda Y., Zhang R., Tanitame A., Tsai Y.-L., Kitagawa I., Chem. Pharm. Bull., 40, 2639-2646 (1992).
23) Kent U. M., Aviram M., Rosenblat M., Hollenberg P. F., Drug Metab. Dispos., 30, 709-715 (2002).

24) Williams P. A., Cosme J., Vinkovic D. M., Ward A., Angove H. C., Day P. J., Vonrhein C., Tickle I. J., Jhoti H., Science, 305, 683-686 (2004). 